\title{
Segurança alimentar, saúde, educação e lazer como fatores de base para desenvolvimento rural de um assentamento do Mato Grosso
}

Food security, health, education and leisure as basic factors for rural development of a settlement from Mato Grosso Brazilian state

\section{La sécuritéalimentaire, lasanté, l'éducation et loisirscommedesfacteurs ala base dudéveloppement d'unnecolonie rural auxledepartmentbresiliéene de Mato Grosso}

\author{
Seguridad alimentaria, salud, educación y ocio como factores de bases para el desarrollo de \\ asentamiento rural de la provincia brasileña de Mato Grosso
}

\author{
Elizabete Maria da Silva* \\ (dasilvabete@yahoo.com.br) \\ Marney Pascoli Cereda*
}

Recebido em 13/08/2013; revisado e aprovado em 25/11/2013; aceito 13/02/2014

\begin{abstract}
Resumo: Esta pesquisa investigou quatro fatores ligados à insustentabilidade social no meio rural, segurança alimentar, saúde, educação e lazer. O local estudado foi o assentamento Padre Josimo Tavares, São José do Povo, MT. Os resultados mostraram que a segurança alimentar foi considerada favorável, embora tenda a piorar com o aumento de idade dos entrevistados. Os demais fatores mostraram-se mais frágeis, levando a considerar que não havia condições propícias para Desenvolvimento Sustentável na época analisada.

Palavras-chaves: Reforma agrária. Desenvolvimento sustentável. Qualidade de vida.

Abstract: These reach investigated four factors linked to social unsustainability in rural areas, food security, health, education and leisure. These settlement studied was located at the Padre Josimo Tavares, São José do Povo, MT. The results showed that food safety may be considered as favorable, although tend to be worsening with the age increasing of the interviewed. The other factors were more fragile, leading to consider that there were no conditions to sustainable developmental in the time analyzed.
\end{abstract}

Key words: Agrarian reform. Sustainable development. Quality of life.

Résumé: La recherche a étudié quatre facteurs liés à la non durabilité sociale dans les zones rurales, la sécurité alimentaire, la santé, l'éducation et loisir. Le locale étudié est Padre Josimo Tavares, São José do Povo, MT. Les résultats ont montré que la sécurité alimentaire pout étre considéré comme favorable, avec la tendance à s'aggraver avec augmentation de l'âgedes répondants. Les autresfacteurs étaient plusfragile, conduisant à qu'il n'y avait pas de conditions propices au développement durable à la epoque analysé.

Mots-clés: Réforme agraire. Développement durable. Qualité de vie.

Resumen: Se investigó cuatro factores vinculados a la insostenibilidad social en las zonas rurales, seguridad alimentaria, salud, educación y ocio. El estudio fue en el asentamiento Padre Josimo Tavares, São José do Povo, MT. Los resultados mostraron condiciones favorables a la seguridad alimentaria, pero que tiende a empeorar con la edad de los encuestados. Los otros factores fueran aunque más frágiles. La conclusión fue de que no existían las condiciones propicias para el desarrollo sostenibles en la época.

Palabras clave: Reforma agraria. El desarrollo sostenible. Calidad de vida.

\section{Introdução}

A reforma agrária brasileira tinha como alvo fixar o produtor rural sem terra, que dela obteria seu sustento. Entretanto a literatura tem registrado êxodo de assentados, principalmente da faixa mais jovem, restando no campo os mais velhos.

Mais recentemente o conceito de sustentabilidade tem sido usado para entender o fenômeno do êxodo. Sem dúvida, se os novos donos deixam a terra, o desenvolvimento não pode ser alcançado permanentemente.

Foi considerado como hipótese da pesquisa que o desequilíbrio entre fatores ligados ao desenvolvimento poderia explicar a desarticulação social, e que esta instabilidade é que inibiria o mecanismo do Desenvolvimento Local, impedindo o protagonismo dos atores envolvidos em seu próprio desenvolvimento. A falta de organização social por sua vez levaria milhares de pessoas ao êxodo e, como

* Universidade Católica Dom Bosco, Campo Grande, MS, Brasil. 
consequência, a estar constantemente recomeçando, sem estabelecer elos ou contribuir de forma relevante para com o desenvolvimento local.

A posse da terra deveria garantir uma base equilibrada entre segurança alimentar, saúde, educação e lazer, selecionados como fatores mínimos para estabelecimento de organização social.

Para avaliar a hipótese, a pesquisa analisou a comunidade localizada no assentamento Padre Josimo Tavares do município de São José do Povo, MT, pela ótica do Desenvolvimento Sustentável, tendo por fatores básicos que devem permitir o processo de desenvolvimento, a segurança alimentar, a saúde, a educação e o lazer.

\section{Revisão bibliográfica}

No modelo de assentamento selecionado no Brasil, a moradia já está garantida com a posse da terra (segurança alimentar, educação, saúde e lazer) foram considerados uma complementação necessária para garantir a satisfação das "necessidades humanas fundamentais", que são a base do Desenvolvimento Sustentável que deveria ser empreendido pelos atores locais para constituir desenvolvimento local.

O Desenvolvimento Sustentável é uma alternativa para o desenvolvimento global. Para Sachs (2004, p. 214), as dimensões do desenvolvimento sustentável são a ecologia, sociedade e economia. O conceito destaca a importância da utilização de meios flexíveis, negociados e contratuais, em que a economia política supera a economia tradicional, como forma de conciliar os clamores econômicos, ambientais e sociais.

Nessa direção, Jared Diamond (2005, p. 17), em sua análise sobre "como as sociedades escolhem o fracasso ou o sucesso", relata um importante conjunto de problemas ambientais que as sociedades modernas enfrentam, traçando um panorama catastrófico, para acentuar a situação em que os recursos naturais não são utilizados de forma sustentável. Segundo o autor, "até mesmo as sociedades mais ricas e tecnologicamente mais avançadas da atualidade enfrentam problemas ambientais e econômicos crescentes, que não devem ser subestimados" (DIAMOND, 2005, p. 17).
Entende-se desejável o desenvolvimento sustentável quando este enseja um processo de mudanças sociais, sejam elas políticas, econômicas ou institucionais, de forma a assegurar a "satisfação das necessidades básicas da população e a equidade social, tanto no presente quanto no futuro, promovendo oportunidades de bem-estar econômico, sendo, além do mais compatíveis com as circunstâncias ecológicas de longo prazo" (JARA, 1998, p. 34). Esse Desenvolvimento tem obrigatoriamente que envolver o ser humano, na satisfação de suas necessidades e no uso sustentável dos recursos naturais. Nesse sentido o desenvolvimento pode ser conceituado como desenvolvimento local quando é fomentado por atores locais, aproveitando as potencialidades existentes no local, desenvolvendo a solidariedade e a cooperação na busca de maior bem-estar próprio e para o entorno, partindo daí para o global (JARA, 1998, p. 34).

O Desenvolvimento Local não deverá depender, necessariamente, dos recursos (financeiros ou humanos) externos à comunidade, sob pena de se tornar insustentável; para isso os recursos internos devem passar por um processo de organização e planejamento em torno de objetivos comuns (ÁVILA, 2000, p. 63).

Sob essa ótica, as Políticas Públicas direcionadas à reforma agrária passaram a complementar o conceito inicial e buscar incluir os conceitos de desenvolvimento local, direcionados não apenas para a distribuição de terras, mas para a preparação do agricultor e da comunidade como um todo, incluindo a produção e desenvolvimento do seu negócio, em vista de se tornar um cidadão independente do Estado (MONTE; PEREIRA, 2009).

Cereda, Vilpoux e Silva (2012), em estudo de caso no Município de São José do Povo, MG, analisaram as migrações que deram origem ao povoado na década de 60 . Usando entrevistas com moradores, concluíram que as migrações decorreram da busca por segurança alimentar. A razão do êxodo foi a dificuldade encontrada em conseguir alimentos em cultivos realizados no município mineiro de origem, onde o meio ambiente havia sido utilizado sem critérios, o que levou à exaustão da terra com dificuldades para garantir a subsistência própria e da família. Chegando o estudo à atualidade, compreendeu-se que 
a abundância inicial de recursos ambientais no local de implantação já caminhava para o esgotamento, e a situação de insegurança alimentar poderia se reproduzir em razão da falta de preocupação com o meio ambiente. Esse movimento dos migrantes caracteriza o efeito do desenvolvimento sem sustentabilidade, ocasionando as mesmas deficiências da região de origem, motivados pela falta de estrutura, de conhecimento e vontade política, entre outros fatores.

Deve-se lembrar que a segurança alimentar extrapola a questão puramente nutricional. Lembra Yasbek (2004, p. 104) que, para atender a segurança alimentar, é necessário o acesso a "alimentos de qualidade, em quantidade suficiente e de modo permanente, com base em práticas alimentares saudáveis e sem comprometer o acesso a outras necessidades essenciais e nem o sistema alimentar futuro". Por essa razão, a segurança alimentar foi destacada entre os quatro fatores selecionados.

Embora os pesquisadores considerem óbvio que, sem segurança alimentar, a saúde é prejudicada, a educação é essencial para seguir esses preceitos e entender as necessidades de uma boa alimentação.

Por outro lado, é bem reconhecido que os níveis de saúde contribuem para a qualidade de vida dos indivíduos e da população. Sabe-se também que um perfil de saúde adequada é um dos componentes da vida social que mais contribuem para uma vida com qualidade (BUSS, 2000).

Essas considerações levam ao questionamento sobre se nos assentamentos há acesso a serviços médico-assistenciais de qualidade. A questão desdobra-se sobre se existem políticas públicas suficientes para conduzir as comunidades a condições saudáveis, com efetiva articulação do poder público e a mobilização dos assentamentos.

Uma vez equacionados a segurança alimentar e a saúde, a educação é, portanto, outro ponto chave por facilitar a seleção e a aceitação da alimentação saudável. Por essa razão, falhas em educação podem desestabilizar a organização social.

Ávila (2003, p. 35) define educação a atitude que permita uma

[...] coesão solidária, que deve ser constantemente educável, no sentido que a comunidade se atualize e impregne, inin- terruptamente, do hábito cultural da incessante pesquisa e discussão de nova forma para se unir, cooperar e agir em direção à consecução de seus próprios rumos de desenvolvimento e concernentes meios de viabilização.

Uma vez que os membros da comunidade alcancem segurança alimentar, saúde e educação, aparentemente todos os fatores exigidos para a sustentabilidade estarão garantidos, mas a Associação Mundial de Recreação e Lazer (WLRA, 2002, p. 01) lembra queé necessário levar em conta o fator lazer, pois o

[...] lazer se refere a uma área específica da experiência humana com seus próprios benefícios, incluindo liberdade de escolha, criatividade, satisfação, diversão e aumento de prazer e felicidade. Abrange formas amplas de expressão e de atividades cujos elementos são tanto de natureza física quanto intelectual, social, artística ou espiritual.

Percebe-se que o lazer é um dos meios para atingir o desenvolvimento pessoal, social e econômico, mas também aspecto importante de qualidade de vida. E preciso questionar se esse tema tem sido considerado nos assentamentos e projetos de assentamentos, uma vez que não foram encontrados relatos na literatura que o abordem nessa conjuntura.

Uma vez apresentados os fatores básicos para a sustentabilidade, resta analisar a situação junto às comunidades no meio rural, destacando-se a evasão do campo.

Em 1988, com o advento da nova constituição, foi garantida a desapropriação do latifúndio improdutivo para finalidade pública e interesse social, o que inclui a desapropriação da terra com finalidade de reforma agrária. Ainda assim não ficou garantida a subsistência do homem no campo, atribuída à falta de ajuda financeira para os camponeses assentados, o que acabou por estabelecer um novo êxodo rural (MORISSAWA, 2001, p.110).

Esse novo êxodo nem sempre tem a fome como causa, mas a situação poderá se agravar na vigência da insegurança alimentar. No Brasil a falta de alimentos não pode ser totalmente atribuída a sua escassez, pois no campo dificilmente há fome. Já foi suficientemente comprovado que, nas regiões agrícolas, mesmo que sem acesso a todos os alimentos necessários a uma alimentação saudável, a fome como tal é quase totalmente inexistente (ABRAMOVAY, 2008). 
Do ponto de vista da pesquisa proposta, o objetivo final da reforma agrária deveria ter como beneficiário o assentado, que deveria se tornar independente, com capacidade para desenvolver sua própria atividade e buscar a estabilidade social, na conquista da cidadania, tornando-se sujeito do desenvolvimento sustentável rural (MONTE; PEREIRA, 2009). Essa conquista inclui a "territorialização", aqui entendida como se apossar do conhecimento local, da educação não formal e da vivência direcionada para garantir a sustentabilidade local.

Importância deve ser dada, portanto, ao lugar como palco dos acontecimentos que perpassam a vida dos indivíduos, onde persiste a busca pela satisfação das necessidades.

Os relatos sobre os assentamentos têm mostrado que a migração é a alternativa mais drástica para a resolução dos problemas enfrentados e pela falta de perspectiva. Goettert (2004, p. 112) analisa as migrações e os diversos sonhos que a impulsionam, "da melhoria das condições de vida, do estudo, da profissão enfim, sonho da terra".

No novo espaço da terra conquistada, o assentado vai buscar recriá-los no seu intimo. A segurança alimentar, educação e saúde e o lazer proporcionam qualidade de vida ao assentado aumentando seus níveis de dignidade. Para a sustentabilidade, aqui considerada como o conjunto da estabilidade social, econômica e ambiental, foi analisada a segurança alimentar, saúde, educação e lazer, considerados básicos para estabelecer as condições para o desenvolvimento. Essas foram as bases para a análise da sustentabilidade no assentamento Padre Josimo Tavares do município de São José do Povo, MT.

\section{Metodologia}

A pesquisa pode ser qualificada como de natureza exploratória que, segundo Beuren (2003, p. 80), é indicada "quando há pouco conhecimento sobre o assunto pesquisado". Considera-se a exploratória adequada uma vez que não foram localizadas informações que tenham previamente utilizado a Segurança alimentar, Educação, Saúde e Lazer, como "fatores básicos" para o desenvolvimento local.

A pesquisa se baseou, como meios, em dados e informações bibliográficas, do- cumentais e de campo. Buscaram-se informações sobre o tema na literatura e foram também coletados, selecionados e analisados documentos locais, no município em questão, com a finalidade de construir um conhecimento teórico analítico que auxilie no estabelecimento das variáveis e estruturação da pesquisa.

A coleta de dados primários utilizou a observação e entrevistas com grupos selecionados como de suma importância para a pesquisa. Para isso foi construído um questionário com questões abertas e fechadas, aplicada às famílias. Como o assentamento não era dividido em glebas que facilitassem a amostragem, utilizou-se uma linha de distribuição de água proveniente de poço artesiano. Usando esse eixo, $46 \%$ do total das famílias domiciliadas no assentamento foram amostradas ao acaso, em um total de 55 famílias. As respostas obtidas na amostragem foram expressas sobre o total das famílias moradoras no assentamento (RICHARDSON, 1999).

\section{Resultados e discussões}

Os dados obtidos no questionário foram analisados como forma de melhor compreender a correlação dos fatores selecionados, segurança alimentar, educação, saúde e lazer na sustentabilidade do local, proporcionando os seguintes resultados:

\section{Caracterização do Assentamento e seus moradores}

Entre acampamento e a divisão dos lotes, o assentamento completou 12 anos em 2009. A faixa etária dos entrevistados do Assentamento Padre Josimo Tavares concentrou-se entre 40 e 60 anos, o que comprova o envelhecimento da população rural local, como já identificado em outros locais (CAMARANO; ABRAMOVAY, 1999).

Somente a metade dos entrevistados era de moradores originais, enquanto outros haviam vendido ou trocado o lote, e uma parte havia chegado ao assentamento nos anos subsequ entes. Esses resultados concordam com os relatos de Pasquis et al. (2005), Mello (2008) e David et al. (1997), que relatam a dificuldade do assentado em se manter no lote. Essas informações reforçam a hipótese 
de falta de sustentabilidade social, econômica ou ambiental (JARA, 1998, p. 34).

Dos entrevistados, pelo menos $32 \%$ haviam participado de acampamento na luta pela terra e tinham ligação com movimentos sociais, mas apenas $22,50 \%$ responderam ainda continuar participando deles na época da pesquisa.

Em relação à infraestrutura e equipamentos presentes no assentamento, constatouse que a energia elétrica estava presente em todos os lotes, mas que, além dessa comodidade, o assentamento não possuía área própria de lazer ou costumes de atividades socializadoras. Faltavam também telefones públicos ou fixos, mas a comunicação era facilitada pelo uso de telefone celular, que $96 \%$ dos entrevistados admitiram usar para comunicação com os familiares, vizinhos e amigos.

A maioria dos entrevistados (56\%) era de origem rural e já havia conhecido a experiência migratória antes de se instalarem em São José do Povo. Menos de 5\% do total de famílias moradoras no assentamento eram de origem urbana, e destes, $15 \%$ migraram diretamente do local de nascimento para o município de São José do Povo. A maioria (85\%) tinha outras origens.

Por sua origem rural, era esperado que conhecessem como produzir pelo menos para subsistência, o que foi confirmado nas respostas, pois para os moradores o objetivo principal da propriedade era a subsistência alimentar. Do total, $43 \%$ das famílias utilizavam a produção da propriedade apenas para a manutenção da família, mas para $57 \%$ o lote era também usado para obter renda com a venda do excedente, confirmando a importância do assentamento na manutenção da subsistência da família (MORISSAWA, 2001, p. 226).

Apesar da alta taxa de analfabetismo, os entrevistados estavam atentos ao que ocorria fora do assentamento. Do total, 39\% declararam já haver mantido contatos na esfera política na tentativa de encontrar soluções para os problemas do assentamento. Mais que isso, 93\% dos entrevistados foram capazes de citar o político no qual haviam votado nas últimas eleições, e apenas 5\% não se lembravam, enquanto apenas um não havia votado.

O nível de confiança entre os moradores é um fator importante no estabelecimento de ligações de sociabilidade. Os entrevistados afirmaram confiar muito nos vizinhos, amigos e parentes e negaram a existência de conflitos, admitidos formalmente apenas por $4,5 \%$, que foram formalmente relacionados à gestão da água enquanto em conversas informais a porcentagem era bem maior. O conflito pela gestão da água devia-se principalmente a uma das associações do Assentamento e chegou mesmo ao registro de queixa no distrito policial do município.

Mesmo que não admitida, a preocupação com a sociabilidade transparecia quando as expectativas do assentado quanto ao futuro foi questionada, e a preocupação com a desunião dos entrevistados foi declarada por $20 \%$ dos entrevistados, citada como o problema mais sério do assentamento por $13 \%$ dos entrevistados.

Apesar de a maioria afirmar confiar nos parentes, amigos e vizinhos, foram relatadas poucas visitas no fim de semana, distanciamento esse comprovado pela baixa relação de "compadrio" existente, confirmada apenas por $22 \%$ dos entrevistados, dos quais $16,5 \%$ entre as famílias mais antigas no assentamento.

\section{Segurança alimentar}

As informações obtidas no assentamento permitiram concluir que havia possibilidade de os moradores se alimentarem bem, com cardápio variado. Todos os entrevistados informaram contar com hortas, pomares e criação de animais para abate, além de derivados do leite. Boa parte do que se produzia era destinado ao consumo próprio, fortalecendo a hipótese de que o objetivo principal da propriedade é garantir a segurança alimentar, como reforçado por Moreira e Lima (2005).

A alimentação básica amilacea era constituída de arroz, feijão, batata doce, mandioca, cará, inhame, etc. Pouca verdura era consumida; o mais comum, alface e couve. Predominava consumo de porco e frango, muito leite e ovos. Foi relatado consumo de muita fruta típica da região, manga, caju, seriguela, goiaba.

Pelo exposto, é possível afirmar que as famílias que habitam o assentamento, de forma geral, contavam com uma base alimentar sólida, o que por si só não constitui Segurança Alimentar. 
Para caracterizar Segurança Alimentar, é necessário que o alimento seja sempre disponível "em quantidade suficiente e de qualidade adequada, proporcionando práticas alimentares saudáveis, e sem comprometer o acesso a outras necessidades essenciais e nem o sistema alimentar futuro, se realizado em bases sustentáveis" (YASBEK, 2004, p. 104).

É importante notar que a análise da faixa etária da população do assentamento mostrou uma população idosa, com concentração entre 40 a 60 anos, o que também foi identificado em outros locais conforme relatado por Abramovay (1999, p. 04). Apenas $16 \%$ dos entrevistados tinham entre 30 e 40 anos, o que caracteriza adultos jovens, possivelmente ainda com boas condições de trabalho no campo. Apenas um jovem foi caracterizado. Apesar de não se constituir em fator alarmante na ocasião, o fato causa preocupação futura.

O acesso aos alimentos no assentamento depende do esforço próprio e, uma vez que as tecnologias mais modernas e informações são raras, dependem de muito tempo e trabalho físico, com prejuízo a outras necessidades consideradas essenciais. Falta de informações também leva à utilização do meio ambiente à exaustão, preço pago pela garantia de alimentação saudável e em quantidade suficiente no presente.

Essa exaustão do meio ambiente fica evidente quando todas as famílias entrevistadas informaram servirem-se da reserva legal obrigatória na propriedade. A grande maioria dos entrevistados (84\%) alegou usar madeira da reserva, o que deverá comprometer o meio ambiente para as gerações futuras, confirmado por $85 \%$ dos moradores que admitiam já ocorrer falta madeira no local, usada para a cozinha.

O meio ambiente era também ameaçado pelos resíduos. Não havia coleta de lixo no assentamento, apesar da proximidade com a cidade. A coleta seletiva poderia ser usada, mas não foi identificada nem mesmo nos municípios vizinhos. Do total, $71 \%$ dos moradores do assentamento informaram queimar o lixo, e não há incentivo à elaboração de composto, embora a maior parte do lixo gerado seja orgânico. Como praticamente todas as famílias afirmaram manter horta e a maioria criar animais, seria importante quantificar esses resíduos da horta e incentivar seu uso como alimentação animal.

Outro fator importante de sustentabilidade, mesmo para segurança alimentar, é a disponibilidade de água. Além do consumo direto como alimento, a água é utilizada para aumentar e garantir a produtividade rural, além de ocasionar bem-estar. Do total, mais de $93 \%$ das famílias responderam que não faltava água no assentamento em razão da implantação de dois poços artesianos. A água era distribuída dos poços para caixas de grande volume, e destas para todo o assentamento. Entretanto, para dispor de água, cada assentado pagava taxa de $\mathrm{R} \$ 20,00$ para até 30.000 litros, a partir do que um adicional de $\mathrm{R} \$ 1,00$ era pago pela utilização de cada 1.000 litros. Na observação do modo de organização local e em conversas informais com as famílias, foi detectado um forte conflito causado pela forma da distribuição da água.

A produtividade no campo depende do nível de formação dos que nele trabalham, para que possam assimilar tecnologias e inovações. Os entrevistados têm essa percepção, pois, quando foram perguntados sobre o que consideravam ser necessário para ser bem sucedido no aumento de produção, a maioria concordou com diversificação da produção.

Para estabelecer a sustentabilidade econômica do assentamento, foi questionado o nível de renda proporcionado por emprego com vínculo empregatício, temporário ou não ou de serviços prestados. Dos entrevistados, $64 \%$ afirmaram sobreviver com um salário mínimo, 19\% com dois salários mínimos e $17 \%$ com uma renda superior a dois salários mínimos, renda essa relativa ao que era produzido na propriedade, complementada com renda de membros das famílias.

Caso considerado que havia energia elétrica e água abundante, a renda obtida era usada para pagar outras despesas que não alimentos, como a água, energia elétrica, transporte, telefone celular etc. Sobre o questionamento de quantos viviam da renda da propriedade, $36 \%$ dos entrevistados tinham família pequena, formada por até três pessoas, $15 \%$ até seis pessoas, e $5 \%$ mais de seis pessoas. Conclui-se que o assentado possuía baixa renda, mas a alimentação estava garantida em razão da produção própria. 
Cerca de $80 \%$ dos entrevistados admitiam complementar renda obtida do cultivo do campo, $50 \%$ dos quais na forma de trabalho informal, fato esse já descrito na literatura (BERGAMASCO, 1997; FURTADO et al., 2004).

Como fica comprovado que a sustentabilidade econômica não existe no lote, e em geral são os jovens que vão trabalhar fora, o trabalho no lote fica então sob responsabilidade dos pais, que, atingindo uma idade avançada, não conseguem mais manter a produção de modo a contribuir no sustento da família.

\section{Educação}

No quesito educação, foi constatado que o estudo era dificultado uma vez que não existia escola no assentamento. O nível de escolaridade local era baixo. Do total, $78 \%$ se declararam analfabetos, alfabetizados parcialmente ou com ensino fundamental incompleto, o que é uma característica da origem como migrantes da zona rural.

Um número expressivo de cerca de 30\% dos entrevistados declarou ter voltado a estudar, e pelo menos $45 \%$ expressaram desejo de fazê-lo, mesmo a distância da escola sendo de mais ou menos $20 \mathrm{~km}$, que podiam levar até duas horas para ser percorrida.

Ao ser perguntado aos pais sobre as aspirações dos filhos jovens, $56 \%$ responderam que os filhos querem ir para a cidade. Os pais acreditam que $38 \%$ gostariam de sair para estudar e 18\% para trabalhar. Quanto à percepção dos pais sobre a permanência no campo, 31\% acreditam que os filhos querem ficar no assentamento, 22\% para continuar o trabalho dos pais e apenas $9 \%$ com o objetivo de conquistar o próprio lote. Ou seja, embora a maioria dos jovens quisesse ir para a cidade para estudar ou trabalhar, seus pais acreditam que parte deles ficaria na propriedade para ajudá-los, mas não repetiriam sua opção de vida.

A educação rural no Brasil possui três vertentes básicas: a educação escolar, a formação profissional, ligada ou não ao Serviço Nacional Rural (SENAR) e a extensão, ligada à Empresa Mato-Grossense de Pesquisa Assistência e Extensão Rural S.A. (EMPAER). Verificou-se que sair para estudar é a única opção para quem queira melhorar seu nível educacional formal, mas deve ser também considerada a formação profissional. Constatou-se, pelas respostas, ser grande o número de assentados que participaram da formação técnica, principalmente quando realizada no assentamento. Do ponto de vista da segurança alimentar, a formação técnica atende as necessidades da comunidade, que acredita ser essa uma forma de melhorar a produção no campo.

Frente ao exposto é possível afirmar que o pilar de sustentabilidade relacionado à educação no meio rural é suficiente para a comunidade envolvida (porque conta com treinamentos), mas não de uma forma mais ampla, pois a comunidade continua com dificuldade de apreender os conhecimentos em razão do alto nível de analfabetismo, parcialmente contornada com demonstrações oral ou prática. A organização social depende de uma escolaridade mais efetiva.

Figueiredo Neto (1998) relata uma série de fatores que ligam o nível da educação à produtividade e renda, em nível macroeconômico. Também relacionam o nível escolar com taxa de crescimento econômico.

\section{Saúde}

Quanto à saúde, o posto que atendia os assentados, também estava localizado na sede do município de São José do Povo. Ainda assim, os assentados e sua família podiam utilizar os serviços de saúde do Município de Rondonópolis, distante $30 \mathrm{~km}$, depois de serem atendidos pelo serviço de saúde no Município. Alguns moradores, com parentes em Rondonópolis, procuravam diretamente o posto de saúde desse Município, dando o endereço de parentes como residência.

As doenças mais comuns segundo os entrevistados são a gripe (74\%), hipertensão $(18 \%)$ e problema de coluna $(6 \%)$ e outras $(2 \%)$ como osteoporose, dores de cabeça, tireoide e gastrite.

Foram relatadas doenças crônicas e graves, que provocam dependência de medicamentos químicos, tais como lúpus, doença de chagas, hipertensão e depressão. Quase todos os assentados entrevistados mostram dificuldade em identificar as doenças crônicas, quando questionados sobre doentes na família. Além da falta de informação, outra 
explicação seria que, pela longa convivência com essas enfermidades, muitas delas, preexistentes em relação à instalação do assentamento, passam despercebidas. Mas a presença dessas doenças crônicas é visível quando se questiona quanto do orçamento doméstico é gasto com medicamentos. Nesse caso, $62 \%$ afirmaram gastar até $10 \%, 9 \%$ até $30 \%, 7 \%$ até $20 \%, 4 \%$ até $50 \%$, mas um entrevistado relatou gastar até $70 \%$ com tratamento de doenças. Ainda assim, muitos ganhavam medicamentos do Sistema Único de Saúde. Outro fator que acentua a existência de doenças crônicas é relacionado com a quantidade de moradores dependentes de medicamentos químicos, que atingia $82 \%$ dos entrevistados.

Dos entrevistados, $48 \%$ admitiram já ter recebido alguma informação sobre como prevenir doenças pela da televisão, que acaba por ser um veículo adequado para informação em razão da alta taxa de analfabetismo. Também foram identificados como agentes de divulgação de informações o rádio, palestras e visitas de agente de saúde no assentamento.

A tradição ainda joga um importante papel nessas comunidades. Do total, 95\% das famílias entrevistadas faziam uso de plantas medicinais, por elas cultivadas e coletadas.

As doenças mais citadas pelos entrevistados podiam ser relacionadas ao trabalho físico, além das deficiências de infraestrutura no assentamento.

Portanto a saúde como fator de sustentabilidade também se mostrou comprometida, com soluções, informações e medicamentos disponíveis com maior conforto apenas na cidade.

\section{Lazer}

O lazer, embora seja bem caracterizado como atividade que promove o bem-estar, é de difícil definição. Pode ser definido como o tempo livre que, por decisão individual, é usado para realizar uma atividade que proporciona bem-estar, desvinculada da produção de bens materiais.

Ao ser perguntado sobre como usava o tempo livre na propriedade, a maioria dos entrevistados quantificou uma média de 22 horas de lazer na semana. Durante esse tempo livre, as opções de lazer mais comuns apresentadas pelos entrevistados foram: televisão
$(20,53 \%)$, descanso $(20 \%)$, visitar e receber amigos $(14,74 \%)$, visitar e receber parentes $(14,21 \%)$, ir à igreja (13,68\%), ir à associação/ cooperativa $(9,47 \%)$, praticar esportes $(04,21)$ e ler $(3,16 \%)$. A grande maioria optava por descansar ou ver televisão como opção de lazer.

Como atividade coletiva de lazer, dois pontos de encontro se destacam. A mais popular são as atividades religiosas, seguida pela participação na associação ou cooperativa. Constatou-se uma disparidade entre os que responderam que a Igreja é uma opção de lazer $(13,68 \%)$ no assentamento e os que responderam que participam de alguma atividade religiosa ( $86 \%$ ). Como não há edificações específicas, "igreja" pode ser considerada as reuniões para as celebrações religiosas nas casas das famílias e no barracão comunitário, o que comprova a importância do fenômeno religioso para a sustentabilidade social nesse grupamento, conforme analisado por Silva e Cereda (2011). No Município as grandes festas são a do padroeiro São José do Povo e o rodeio, que atraem moradores de toda região e regiões circunvizinhas.

Se as opções de lazer no assentamento são limitadas, essa limitação pode ser em parte justificada. As barreiras socioeconômicas, a baixa organização social, os atritos e o baixo nível educacional criam todo um clima favorável para tal opção, portanto o lazer se torna uma atividade passiva, um assimilador de tensões, algo que ajuda a conviver com as injustiças (MARCELINO, 2000).

Embora, segundo as próprias informações dos assentados, aproximadamente 22 horas na semana seriam disponíveis para lazer, uma análise mais detalhada mostra que o morador não conseguiria dispor de todo esse tempo de uma vez. As atividades desenvolvidas na área rural não podem ser interrompidas ao final da semana. Há necessidade de molhar as plantas, alimentar e tratar os animais todos os dias.

\section{Considerações gerais}

Apesar das dificuldades apresentadas em relação aos fatores que precedem o desenvolvimento local, segurança alimentar, educação, saúde e lazer, os assentados demonstraram satisfação com a vida no assentamento. Do total, $77 \%$ dos entrevistados 
responderam acreditar que se vive melhor no campo que na cidade. Embora apontando as dificuldades em serem atendidos em quesitos como saúde e educação, os moradores foram unânimes em apontar que a vida no campo é mais prazerosa para relacionar-se com as pessoas e se divertir.

Das famílias entrevistadas, $73 \%$ consideram a vida no assentamento como boa, pois conseguiam produzir uma alimentação rica e variada, proporcionando saúde e bem-estar físico aos familiares, mesmo com insegurança quanto ao futuro. No entanto a produção em nível de subsistência consome tempo e esforço, não sobrando muito para os fatores que proporcionam a socialização, tais como a educação e o lazer. A educação, fator primordial para que ocorra o desenvolvimento, é também um fator comprometido em razão da baixa escolaridade dos moradores e da dificuldade em sanar o problema, devido ao pouco tempo no lote e à distância da escola.

Dos principais problemas relacionados pelos entrevistados, nenhum envolveu critérios ligados à segurança alimentar. A educação e lazer também deixaram de ser citados. Pela ordem os problemas mais sérios foram transporte $(45 \%)$, estradas $(15 \%)$, desunião $(15 \%)$, recursos governamentais $(6 \%)$ e saneamento básico (04\%). A falta de um posto de saúde foi lembrada por $15 \%$ dos entrevistados, constituindo-se no único item entre os três fatores selecionados como necessários ao desenvolvimento local.

Portanto, na época em que a pesquisa foi realizada, pode-se afirmar que a população do assentamento Padre Josimo Tavares não dominava os fatores de base considerados como fundamentais para alavancar o desenvolvimento local. Também não havia indícios de desenvolvimento sustentável de forma social, econômico e ambiental, garantindo um processo de mudanças sociais, tanto políticas econômicas e institucionais, fomentado por atores locais, aproveitando as potencialidades existentes no local, desenvolvendo a solidariedade e a cooperação na busca de maior bem-estar próprio e para o entorno, partindo daí para o global.

\section{Referências}

ABRAMOVAY, R. Agricultura familiar e desenvolvimento territorial. Reforma Agrária - Revista da Associação Brasileira de Reforma Agrária, Campinas, SP, v. 28 n. 1,
2 e 3, jan./dez. 1998; v. 29, n. 1, jan./ago. 1999. Disponível em: <http://www.econ.fea.usp.br/abramovay/ artigos_cientificos/1999/Agricultura_familiar.pdf>.

Integrar sociedade e natureza na luta contra a fome no século XXI. Cad. Saúde Pública, Rio de Janeiro, v. 24, n. 11, nov. 2008. Disponível em: <http://www.scielo. br/scielo.php?script=sci_arttext\&pid=S0102-311X20080 01100026\&lng=pt\&nrm=iso>. Acesso em: 13 ago. 2013. http://dx.doi.org/10.1590/S0102-311X2008001100026. ASSOCIAÇÃO MUNDIAL DE RECREAÇÃO E LAZER - WLRA. Carta internacional de educação para o lazer. In: SEMINÁRIO INTERNACIONAL DA WORLD LEISUREAND RECREATION ASSOCIATION DE EDUCAÇÃO PARA O LAZER, Jerusalém. Proceedings... Jerusalém, 2002. Disponível em: <http:/ / www.saudeemmovimento.com.br/conteudos/conteudo_exibe1. asp?cod_noticia $=195>$.

ÁVILA, V.F. Cultura, Desenvolvimento Local, solidariedade e educação. Conferência ministrada em 27/11/03. Campo Grande, MS, 2003, p. 35-36. Disponível em: <http:// www.ucdb.br/coloquio/arquivos/Fideles.pdf $>$.

Pressupostos para a formação educacional em Desenvolvimento Local. Interações, Revista Internacional de Desenvolvimento Local, Campo Grande, MS, v. 1, n. 1, p. 63-76, set. 2000.

BERGAMASCO, S. M. P. P. A realidade dos assentamentos rurais por detrás dos números. Estudos Avançados, São Paulo, v. 11, n. 31, p. 37-49, 1997.

BEUREN, I. Como elaborar trabalhos monográficos em contabilidade: teoria e prática. São Paulo: Atlas, 2003.

BUSS, P. M. Health promotion and quality of life. Ciência e Saúde Coletiva, Rio de Janeiro, v. 5, n. 1, p. 7-18, 2000.

CAMARANO, Ana Amélia; ABRAMOVAY, Ricardo. Êxodo rural, envelhecimento e masculinização no Brasil: panorama dos últimos 50 anos. Rio de Janeiro, janeiro de 1999. Diretoria de Pesquisa do IPEA. Departamento de Economia e Procam/USP. Disponível em: <http:/ / www.dominiopublico.gov.br/download/texto/ td_0621.pdf $>$. Acesso em: 23 set. 2009.

CEREDA, M. P.; VILPOUX, O. F.; SILVA, E. M. Migrações, posse da terra e segurança alimentar: Estudo de caso do povoamento do Município de São José do Povo, Mato Grosso, Brasil. Portuguese Studies Review, v. 17, p. 30-60, 2012.

DAVID, M. B. de A.; WANIEZ, P.; BRUSTLEIN, V. Atlas dos beneficiários da reforma agrária. Estudos Avançados, São Paulo, v. 11, n. 31, p. 51-68, set./ dez. 1997. Disponível em: <http:/ / www.scielo.br/scielo.php?pid=S0103$40141997000300004 \&$ script=sci_arttext\&tlng=ES>.

DIAMOND, J. Colapso: como as sociedades escolhem o fracasso ou o sucesso. São Paulo: Record, 2005. 685p.

FIGUEIREDO NETO, Leonardo F. Determinantes da participação no mercado de trabalho e dos rendimentos e retornos aos investimentos em Capital Humano. Análise Econômica, Porto Alegre, ano 16, n. 29, p. 67-86, mar. 1998.

FURTADO, E.; SIMÃO, R.; LEMOS, A. Análise do consumo de oxigênio, freqüência cardíaca e dispêndio energético, durante as aulas de Jump Fit. Rev. Bras. Med. Esporte, Niterói, RJ, v. 10, n. 5, p. 371-375, set./ out. 2004. 
GOETTERT, J. D. O espaço e o vento: olhares da migração gaúcha para Mato Grosso de quem partiu e de quem ficou. 2004. 466p. Tese (Doutorado em Geografia) - Universidade Estadual Paulista, Presidente Prudente, SP, 2004.

JARA, C. J. A sustentabilidade do Desenvolvimento Local. Brasília: Instituto interamericano de cooperação para a agricultura (IICA); Recife: Secretária do planejamento do Estado do Pernambuco-Seplan, 1998. 316p.

MARCELINO, N. C. Estudo do lazer: uma introdução. 4. ed. Campinas: Autores Associados, 2000. 100p.

MELLO, P. F. Coesão social e evasão em assentamentos rurais no extremo-sul do Brasil. Cad. CRH, Salvador, BA, v. 21, n. 54, p. 592-610, set./dez. 2008. Disponível em: <http:/ / www.cadernocrh.ufba.br/viewarticle. php?id $=479 \&$ OJSSID $=89 \mathrm{c}>$.

MONTE, P. A. do; PEREIRA, A. E. daS. Um estudo regional dos determinantes da geração de renda e construção da cidadania nos Projetos de Assentamentos. Rev. Econ. Sociologia Rural, Brasília, v. 47, n. 4, dez. 2009. Disponível em: <http:/ / www.scielo.br/scielo.php?script=sci arttext\&pid=S0103-20032009000400010\&lng=en\&nrm =iso>>. Acesso em: 4 ago. 2013.

MOREIRA, R. J.; LIMA, E. N. de. Identidades sociais e assessoria técnica: agricultores assentados e assentamento.
JORNADA DE ESTUDOS SOBRE ASSENTAMENTOS RURAIS, 4 . Texto de apoio ao curso de atualização para os técnicos da ATES (Assessoria Técnica, Ambiental e Social). Convênio CPDA/REDES - NEAD/INCRA. Março 2005. Disponível em: <r1.ufrrj.br/cpda/ruralidades/arquivos/arquivos_producao/6_ARQ.doc>.

MORISSAWA, M. A história da luta pela terra e o MST. São Paulo: Expressão Popular, 2001. 256p

PASQUIS, R.; SILVA, A. V. da; WEISS, J.; MACHADO, L. "Reforma agrária" na Amazônia: balanço e perspectivas. Cadernos de Ciência \& Tecnologia, Brasília, v. 22, n. 1, p. 83-96, jan./abr. 2005.

RICHARDSON, R. J. Pesquisa social - métodos e técnicas. 3. ed. São Paulo: Atlas, 1999, 270p.

SACHS, I. Desenvolvimento includente sustentável sustentado. Rio de Janeiro: Garamond, 2004. 151p.

SILVA, E. M.; CEREDA, M. P. Contribuição da religião para com o desenvolvimento local: estudo de caso da organização "Dando as Mãos". Interações, Campo Grande, SM, v. 12, n. 1, jan./jun. 2011.

YASBEK, M. C. O programa fome zero no contexto das políticas sociais brasileiras. São Paulo Perspec., São Paulo, v. 18, n. 2, p. 104-112, abr./jun. 2004. 